selnd mit concentrirter Schwefelsäure und zuletzt mit einer sehr concentrirten Aetzkalilauge, mit welcher man es noch einige Tage lang in Berührung lässt, und rectificirt dann das nun völlig von fremden Beimischungen befreite $\mathrm{Oel}$ in einer Glasretorte mit angelegter Kühlröhre. (Polyt. Notizbl. 1853. No. 20.)

$B$.

\title{
Ueber den Stickstoffgehalt der Revalenta arabica.
}

Wiewohl es sich längst herausgestellt hat, dass die Revalenta arabica ihrer physikalischen Eigenschaften nach das Mehl einer Papilionacee ist, so kann es doch nicht ohne Interesse sein, auch über die Aschenbestandtheile und den Stickstoffgehalt derselben weitere Mittheilungen zu erhalten. Dr. Walz erhielt aus 6 verschiedenen Bezugsquellen Revalenta, sie war der Farbe nach, wenn auch nicht ganz gleich, so doch ziemlich ähnlich und stets röthlich, wie das Mehl von Vicia sativa, var. alb. gefärbt. In einer grösseren Versammlung von Oekonomen, Gewerbtreibenden und Kaufleuten wurden die 6 Proben der ächten Revalenta ausgestellt und gleichzeitig das Mehl von Vicia faba, Ticia sativa, Thasaeolus vulgaris, Erum Lens, aber keiner der Anwesenden konnte durch den Geschmack die ächte Revalenta herausbringen; alle stimmten darin überein, dass sämmtliche Mehlsorten, wenn nicht ganz gleich, so doch wahrscheinlich derselben Pflanzenfamilie entnommen sein müssten!

Ls wurde nun der Wassergehalt der ächten Revalenta bestimmt, er betrug im Durchschnitt 7 Proc. Jener der Asche nahezu 2,08 Proc. Dic verschiedenen Mehlsorten unserer heimischen Leguminosen enthielten 8 Proc. Wasser und liefern 2,51 Proc. Asche.

In den einzelnen Sorten der angeblich ächten Sorten fand sich folgender Gehalt an Stickstoff. Von Sorte No. 1. aus einer hiesigen Apotheke entnommen, vollkommen im Dampfbade getrocknet, wurden 2 Verbrennungen mit Natronkalk vorgenommen.

1) 0,635 Grm. gaben Platinsalmiak 0,342.

2) 0,516 Grm. gaben Platinsalmiak 0,278. Es berechnet sich sonach aus No. 1. der Stickstoffgehalt in 100 Th. derselben auf $0,0334$.

Von der Sorte No. 2. aus der zweiten hiesigen Apotheke bezogen, die von Farbe wenig heller war, gaben 
1) $0,518 \mathrm{Grm}$. bein Verbrennen mit Natronkalk 0,276 Grm. Platinsalmiak.

2) 0,640 Grm. auf dieselbe Weise behandelt 0,341. Von dieser Probe ergiebt sich auf 100 Th. ein Stickstoffgehalt von 0,0329 .

Die dritte Probe, aus Darmstadt erhalten und von Farbe etwas dunkler als die beiden andern, lieferte:

1) aus 0,567 Grm. Platinsalmiak 0,311.

2) von 0,520 Grm. erhielt man Platinsalmiak 0,279; auf $100 \mathrm{Th}$. Revalenta, also 0,0335 Stickstoff. Aus diesen 3 Bestimmungen geht hervor, dass der Stickstoffgehalt nicht sehr abweichend ist und mit vielen anderen Mehlsorten in gutem Verhältniss steht. Die Asche, welche etwas schwierig von aller Kohle befreit zu erhalten ist, enthält:

Kali.

Natron.

Kalk.

Magnesia.

Phosphorsäure.

Schwefelsäure.

Salzsüure.

(Neues Jahrb. f. prakt. Pharm. Bd. 1. Heft 4.) B.

\section{Bestandtheile der Cacaobutter.}

C. Specht und A. Gössmann haben die Cacaobutter untersucht und gefunden, dass sie aus Stearin, Palmitin und Elain besteht, und dass die Stearinsäure sich in so vorherrschendem Maasse darin befindet, dass die Cacaobutter als eins der besten Materialien zur Darstellung grösserer Mengen reiner Stearinsïure zu betrachten sein möchte. Frühere Versuche mit der Cacaobutter sind unvollständiger ausgeführt, Boussingault fand sie nur aus Stearin und Elain zusammengesetzt; Stenhouse bestätigte das Vorhandensein von Stearinsäure, hielt die Anwesenheit von Margarinsäure nicht für unwahrscheinlich und schloss aus dem Auftreten von Fettsäure in dem Destillationsproducte auf die Gegenwart von Oelsäure. (Ann. der Chem. u. Pharm. XC. 126-128.) G. 